Journal of Transformative Praxis

Vol. 1, No. 1, 2020, pp. 9-24

Received: 31 March 2020; Revised:12 May 2020; Accepted: 12 June 2020

Original Article

\title{
Connecting Mathematics Education to my Relationship with the Cosmos
}

\author{
Jiju Varghese \\ St. Xavier's College, Kathmandu, Nepal \\ Email: jkevillil@gmail.com \\ 0000-0002-2967-221X
}

\begin{abstract}
I believe that human beings are closely interconnected to the cosmos in which we exist. Today, we hear a lot about caring for the Mother Earth. More and more humans are coming to realize the need to protect our environment and to stop the uncontrolled exploitation of the nature. With the exploration of the space, we have also come to understand that we are only a tiny particle in this vast cosmos. As a result, we are responsible towards the cosmos that surrounds us and in which we are part of. Often mathematics teaching-learning has been limited to the cognitive level and very seldom concerns of the ecology and issues related to the cosmos are brought up in mathematics classrooms. My mathematics teaching-learning life was no exception as there was hardly any connection to my relationship with the cosmos. Through this autoethnographic study, I show how mathematics teaching-learning needs to and can take into consideration the important relationship and responsibility we have towards the environment, universe and the cosmos and how we can teach pro-cosmological behaviours to our students through topics in mathematics they are learning. This will be done by narrating my lived experiences of missing the link with the cosmos in my mathematics classrooms both as a student and a teacher and by presenting a few examples of making mathematics teaching-learning cosmologically responsible in classrooms.
\end{abstract}

Keywords: Relationship. Cosmologically responsible. Pro-cosmological behaviours. Connecting and Caring.

\section{Introduction}

This article is a section of my MPhil thesis about relationship responsible mathematics in which I inquired about the connection of mathematics teaching-learning to my relationship with the cosmos, others, Transcendental, and the self. In this article, I take up the connection of mathematics teaching-learning to my relationship with the Cosmos. This is an autoethnographic inquiry in which I look at my life as a student of mathematics in school and 
university days, as a Jesuit, as a mathematics teacher, and finally as an MPhil student of Mathematics Education. While doing so, I bring in narratives that are related to the topic under study from my teaching-learning experiences of mathematics during the above stages.

\section{Setting the Background}

Today, the care of Mother Earth is a major concern. More and more human beings are coming to realize the need to protect the environment and stop the uncontrolled exploitation of nature. Climate change, ozone layer depletion, extinction of many species, melting of the glaciers and the arctic zone are all much talked about these days. There is a sudden surge in talking about the impact of human behaviour on the planet and the responsibility of human beings in taking care of it. For example, in a recent interview, Stephen Hawking, the noted cosmologist and physicist, claimed that human beings have only 100 years to colonize another planet against his earlier time limit of 1000 years. According to him Planet Earth is heading for doom due to climate change, over-population and possible asteroid strikes (Holley, 2017).

With the exploration of space, we have also come to understand that we are only a tiny particle in this vast cosmos. As Stephen Hawking said once, "In less than a hundred years, we have found a new way to think of ourselves. From sitting at the centre of the universe, we now find ourselves orbiting an average-sized sun, which is just one of millions of stars in our own Milky Way galaxy" (Hawking, n.d.). Carl Sagan, another noted cosmologist, also emphasized this cosmic nature of ours through his writing and shows. These scholars invite us to become cosmic in our thinking, attitudes, and behaviour.

Similarly, many spiritual writers talk about our cosmic nature and our deep connection to the cosmos instead of the immediate environment and Planet Earth (Krishnanada, n.d.; Painadath, 2009; Pope Francis, 2013; Tolle, 2003). I see a greater interconnectedness with Planet Earth, the living and nonliving beings, the solar system, the stars, the galaxies, and everything that exists in the universe. Riley-Taylor (2002) suggests that education should teach students to be aware about their place in the cosmological order and the need for them to be cosmological in their views. Further, I also believe that our space explorations, nuclear programs, air travels, radar technology and missile programs will eventually have unforeseen negative impacts, not just on our planet but on the cosmos as a whole.

Consequently, I would like to use the term cosmological, instead of the usual terms like ecological and environmental, since it encompasses everything that is part of the universe. We should not limit our connection just to Planet Earth alone but must extend it to the whole universe. Further, our relationship with the cosmos must encompass everything that is part of it. The present crisis that threatens the cosmos is due to the inappropriate relationship of human beings with nature (Lieflander et al., 2013). The existence of future generations hinges on how our relationship with the cosmos is understood and lived in the present. Thus, developing the right type of relationship with the cosmos is indispensable and the need of the hour.

Mathematics being a major player in the development of technology bears a huge responsibility in developing this right relationship. The International Commission on Mathematical Instruction in 2011 talked about how mathematics has been part of almost everything that happens around us. However, very seldom mathematics teaching-learning is directly associated with such a relationship. Mathematics teaching-learning has been mostly academic and intellectual focusing on learning the steps, memorizing the formulas and processes and reproducing them during exams to score marks. It has suffered from a 'disconnect and alienation' between what is taught and the life of the students and teachers 
alike. There is no surprise then that relationship with the cosmos was not one of the priorities of mathematics teaching-learning.

As I reflected over my relationship with the cosmos, many questions began to emerge. Why was the concern for Mother Earth and the cosmos never a part of my teachinglearning of mathematics? Now that I realize the need for it, how can I promote the right relationship with the cosmos in my mathematics classroom? How can I teach proenvironmental behaviours through mathematics? (Kollmuss \& Agyeman, 2002). How can the teaching-learning of mathematics enable students and teachers to become persons who understand their place in the vast cosmos and who are responsible for caring for the cosmos? How can mathematics help students and teachers to develop the right type of relationship with the cosmos? In other words, how can mathematics become cosmologically responsible?

\section{Methodological Journey}

I wanted my research to be a reflective journey to find answers to the above questions and thus discover the importance of connecting mathematics teaching-learning to my relationship with the cosmos. This article is then an autoethnographic inquiry through which I enter into a personal, retrospective and introspective journey of my life as a mathematics student and teacher. In this reflective, critical and personal voyage, I explore my teaching-learning of mathematics in relation to my relationship with the cosmos. I have attempted in this autoethnography to detail, explain and make meaning of my experiences as a mathematics teacher and learner in connection with my relationship with the cosmos. I am both the researcher and the primary participant of this study. The primary source of data for this study is my lived experiences of mathematics teaching-learning in the context of my relationship with the cosmos.

I have involved a relativist ontology based on multiple and contextual realities personally constructed through my experiences as a school student, as a university student, as a Jesuit, as a teacher and as an MPhil student besides through the lenses of my students and teachers. The epistemological approach that I have taken in my study is critical subjectivity. The nature and form of the knowledge that is explored in my study is subjective, based on my lived experiences and derived from critical reflection on those experiences. By critically looking at my experiences I have been able to derive new meaning and knowledge (Mezirow, 1997, 2003). The primary value that has guided me in this study is transformation; transformation of myself into a better teacher and my students into better human beings which will eventually lead to wider transformation in society, especially in the way we relate to the cosmos.

Being a transformative research that embodies research as learning, there are elements of many paradigms in my study. I have been an interpretive researcher in the way I have looked at how mathematics teaching-learning was connected to my relationship with the cosmos. I have applied critical paradigm to help me develop critical self-awareness and critical understanding of my experiences of mathematics teaching-learning in relation to the way I engaged with the cosmos. I have applied the postmodern paradigmatic approach in telling my experiences using various genres of narratives, stories, poems, anecdotes, metaphors and imageries, to make what I wrote more "realistic, plausible or believable and thus engage the readers in critically reflecting on their own experiences" (Taylor \& Medina, 2011 , pp. 10 -11). To ensure honesty and integrity of my inquiry, I have attempted to use quality standards like verisimilitude as lifelikeness, transferability as viability, pedagogical thoughtfulness, incisiveness as a focus and critical reflectivity as transformative process (Luitel, 2012). These standards have enabled me to create a comprehensive account of my experiences assuring fairness, authenticity and meaningfulness. 


\section{The Bagmati Connection}

The foul draft from the Bagmati River made me breathe sparingly. I was on my bicycle as usual along the river corridor. I wanted to avoid the heavy traffic on the main roads. As I was pedalling, I looked into the river to see the blackish water of this holy river. I have heard a lot of people talking about how it was in the past. Every Saturday, I have also read about the Bagmati cleaning campaign which has gone beyond a year as of now.

Earlier in the year, during the monsoon too, I had cycled by the river on many occasions. Water in the river was not blackish. It was muddy but not blackish and there was no foul smell. Rather it had a pleasant monsoon smell. The river was swollen, the water level was very high and current very strong. I could not find many traces of the sewer that it used to be. Not only the colour but the smell of the water was entirely different.

I wondered what happened to this river. It pained me because there is a river that is very close to my heart. It takes me to my childhood days in Kerala, India. It is there that I first discover the alienation of mathematics from my relationship with the cosmos.

\section{On the Lap of Nature: My Childhood}

My childhood was always connected to nature. I can claim that I grew up in the lap of nature for all practical purposes. My house was in the middle of a small property surrounded by trees and plants. There were rubber trees, coconut trees, jackfruit trees, nutmeg trees, banana trees, fruit trees and many other trees one can find only in Kerala. At a very young age I learned to climb trees and enjoyed doing it whether for fun or for plucking fruits, coconuts or nutmegs. We always had cows, goats, chickens and ducks at our home, sometimes cats and dogs too. Taking care of them was a major responsibility for us children. It was as important as our studies. As a result, there was constant and close interaction with nature during my childhood onwards and my life was so connected to it and I can't imagine a life without it those days.

I was also blessed to live next to a river and my life was very much connected to it. The river lies to the eastern border of our property, hardly 25 meters away. If I stepped out of our property I would end up in the river. The river always had plenty of water since its origin was from the famous Idukki dam and the hydropower project which is the main source of electricity in Kerala. The water was very clean and serene during the dry season but would swell up during the monsoon. The water level would rise all the way up to our house during those seasons, inundating a lot of land and roads upstream and downstream. One of the things I have always wondered was about the volume of water needed to fill the river so much, inundating the bank and nearby areas. Another mathematical calculation I used to do was to count the number of steps already covered and would be able to figure out the fields of our neighbourhood where water had already entered. During the flood season, one of the first things that I did was to go to the river and figure out the level of water that arose or decreased looking at the steps and the marks that remained.

During the holidays, I spent a longer time in the river swimming and playing various games along with my friends. Diving was an important part of these games and a lot of mathematics was involved. If I did not place my body at the proper angle at the time of impact, I used to get hurt especially in the chest. Where the water was shallow, I needed to ensure that I shifted the motion of the body at the right time so that I did not hit the riverbed. Yet another fun activity we friends used to have was in finding out who could move under water the farthest. We did this by propelling our body using our toes. 
There was a canoe service to take people across the river. I learned how to row it by the time I was in class five, like my brothers. Using the canoe successfully involved plenty of mathematics. Depending on the level of water, the current of the river, the type of canoe and the load in the canoe, one had to calculate how much force is applied on the bamboo stick or the paddle and how far up one had to go before changing direction to the other bank.

Another very important relationship I had with the river was through fish. The river had plenty of fish and we went for fishing daily except during the flood season. As I look back, I see how mathematics was involved in the catching of the fish. The ottaal (bamboo trap) that we used for fishing had a perfect circular narrow opening at the top and a much wider one at the bottom. Depending on the type of water, it had to be placed with great precision and timing to trap fish. In still water it was relatively easier, whereas in the flowing water the task became more difficult depending on the current and the movement of the fish.

My life thus was so closely linked to nature, living in a place that could boast of incomparable natural beauty and splendor. Environmental connection was experienced at every moment of my life and many of these connections had mathematics involved in them even though I was not aware of it. Even though I lived very close to nature, I am not sure if I was ever aware about the importance of caring for the environment and nature during my school days. In fact, I do not remember anyone talking about the importance of caring for nature during those days, whether in the school or elsewhere. Some of the practices we had actually went against caring for nature. For example, with friends we used dynamite blasting for catching fish which killed all types of fish, big or small, and any other aquatic life present in the area concerned. The river was the easiest place to throw things that we did not need, hoping that the river would take them eventually to the sea, without knowing how it would affect the river and the people downstream.

My school did not impart much in terms of caring for the environment. Kerala being one of the most naturally blessed places in India, environment was probably taken for granted then. We did not have any subject which directly dealt with environmental issues. We studied general subjects like mathematics, science, social sciences and three languages. It is no surprise then that mathematics had nothing to do with caring for the environment. It was 'pure' mathematics and nothing else. Even my use of mathematics in daily life was more spontaneous than what I learned in the classes. Plenty of mathematical concepts were involved while counting coconuts, and for transactions, while riding the canoe, while swimming across, diving and fishing. I learned very little of these calculations from my mathematics classes. More unfortunately, there was never any mention of caring for the nature in my classes. However, I learned many valuable lessons on it from my elders and experiences. I remember one such incident which taught me lessons that are paramount in my present life.

\section{School of Life versus School of Mathematics}

The year was 1988. I was in class eleven. We had recently renovated our house. The work was complete and things were going smoothly for a few months till we encountered a problem. My mother brought it to our notice, "The waste water from the kitchen is getting collected in the yard and it is beginning to stink. We need to do something about it." We had expected the water to be absorbed into the soil in the yard and the land nearby. But, over time, it had started spreading out instead of going down. We needed a solution. The more educated persons in the family, my two elder brothers and I, looked for a solution.

Being the most intelligent in terms of marks, I suggested, "Why not send the dirty water to the river?" Others too thought it was a wonderful idea. I was in the mathematics stream of class 11 . So, I took the initiative in finding out the length and the radius of the pipe 
needed in implementing the solution and the slope needed to ensure that the water flowed smoothly. All we needed now was the permission and money needed. When our father came back from work, we told him our brilliant idea.

"No, that is not a brilliant idea! It will dirty the river, degrade the water and affect people downstream" he told us.

I disagreed, "But our wastewater is very little in comparison to the water that is in the river. Besides, the current is strong, and will flush away everything. Nobody is really going to notice." My mathematics brain started retorting by presenting the logic behind our brilliant idea.

My father countered us, "Imagine if everyone living near the river did the same. If the waste water from the households of Thodupuzha (i.e., a town upstream) was sent to the river? Do you think you will feel comfortable enough to drink it or even take a bath in it? Is it not the same for the others downstream? Think about all the fish that we get to eat. Do you think they will have any chance in wastewater?" I don't think any of us really comprehended what he was trying to say, or the serious consequences of our brilliant idea. All we could think about was a solution to our problem.

"So, what else can do we do then?" one among us must have asked. "Let us try something else." He gave his idea. He told us to dig a pit of a particular size. We filled it with rocks and gravel and connected the kitchen wastewater outlet to this soak pit. I still used my mathematics to get the pit of the right size, this time for a good cause. Surprisingly this pit still serves us even after 30 years and for a new house too.

My father was only a class six educated mechanic. In those days, we hardly heard anything about environmental degradation or sustainable development in our area. Yet he knew well the results of our actions on the ecology. Life taught him which schools and mathematics lessons did not teach me or my brothers.

When I reflect over that incident now, I see the wisdom of my father. I realized that if we knew wastewater and sewage were mixed in the water, we would not have been comfortable in entering into the river as we used to. Our relationship with the river would have been different in many ways, like it is with the Bagmati River now. We would not have liked to take a bath or swim in such a river. All the water that I drank during my swimming expeditions and all those tasty fish that I caught would have resulted in a different story altogether. Even now, when I visit my parents, one of the first things that I do is to go for a swim in the river no matter how late into the night it is. The water level is neither as high as it used to be nor is the water as clean as it was in my school days. Yet, I cannot disconnect from that river so easily.

\section{So Near Yet So Far}

My relation to the cosmos is one of the four relationships (With God, others, nature and oneself) that define me as an integral human being (Pope Francis, 2013). However, this component was never part of my mathematics classes. I consider my school days as a perfect example of how alienated my mathematics learning was from cosmological concerns in general and environmental concerns in particular. As narrated in the above stories, my mathematics classes were devoid of any references to my relationship to the cosmos. On the one hand, I was living a life very close to nature outside the classroom, but had no connection to it inside the class, on the other hand. There was this dichotomy that I experienced during my school days. My classes never indicated anything about how I was a tiny speck in the vast universe, how I was closely related to the other living and non-living beings in the universe. My classes were focused merely on cognitive activities. Further my mathematics classes failed to teach me about my responsibility towards caring for the cosmos. I did not 
learn from my mathematics classes which of my behaviours were harmful to the cosmos. Neither did I learn to develop pro-cosmological behaviours (e.g. saving water and electricity, avoiding plastics and using reusable things, opting for public transport, proper management of waste etc.) (Kollmuss \& Agyeman, 2002) to care for the cosmos and everything in it.

Schools have a major role to play in instilling pro-cosmological behaviours in children. Coertjens et al. (2010) in their study clearly bring out this conclusion. They say "schools do have an impact on students' environmental awareness and attitudes and can, therefore, be drawn upon by Environmental Education policy makers as means of fuelling students' awareness and attitudes" (p. 242). They further suggest that schools should use activities that can kindle in students a caring and pro-environmental attitude towards the environment. It is interesting to note here that they do not mention any particular subject to be responsible for creating environmental awareness among students. They consider schools one unit responsible for it and everything that happens in schools must promote in students their role in the cosmos, their responsibility towards it. As a result, mathematics teachinglearning too must become cosmologically responsible. My learning of mathematics in my school days failed in this regard.

Another angle of looking at this is from the point of view that I lived a life very close to nature. I had direct contact with nature all the time. I lived with it, in it and of it. Nature was an integral part of me. Ideally speaking, that should have been a fertile ground for proenvironmental behaviours and attitudes, provided someone had sowed the seeds. This notion is expressed by Duerden and Witt (2010) when they say, "It appears that a combination of both indirect and direct experiences that provide opportunities for both the attainment and application of environmental knowledge and attitudes, coupled with the promotion of perceived freedom, is an effective method of promoting pro-environmental behavior" ( $p$. 391). In my case, my direct experiences with nature and the use of mathematics in my day-today activities would have been strong catalysts for imbibing a genuine love for the cosmos and responsibility towards it. However, such a connection was never made in my mathematics classes. The only ones who made such a connection were probably my parents and elders, even though I did not understand it at that time.

Chawla and Cushing (2007) mention how childhood experiences are considered to be significant and formative experiences in terms of developing pro-cosmological behaviours. According to them, "nature activities in childhood and youth, as well as examples of parents, teachers and other role models who show an interest in nature, are key 'entry-level variables' that predispose people to take an interest in nature themselves and later work for its protection" (p. 4). They also emphasize the pivotal role played by teachers and education in the lives of environmental activists. Even though their study does not focus on a particular subject, the role of learning mathematics and mathematics teachers is also inherent to their theory about imparting proper cosmological behaviours among students.

My mathematics learning in school failed in yet another aspect. I missed one of the crucial elements of integral education as seen from the point of view of the Ignatian Pedagogical Paradigm (IPP). Proper application of the five components of IPP: context, experience, reflection, action, and evaluation, would have helped me to "make conscious, responsible choices" (McAvoy, 2013, p. 64) with regard to my relationship with the cosmos. Understanding my context of being close to nature, my learning and other experiences inside and outside the classroom should have led me to a deeper reflection on my responsibility towards the environment and cosmos. This in turn would have enabled me into procosmological actions. Consequently, evaluation would not have been focused just on what I learned cognitively but also on what I have learned for my life in my responsibility towards the cosmos, for the present and the future. The saga of this disconnection continued even during my university studies. 


\section{University Studies: Away from the Lap of Nature}

My University studies were in two of the biggest cities in India, Mumbai and Chennai. The subjects that we learned were integration, differentiation and other calculus topics, transformations, groups and subgroups, discrete mathematics, real and complex analysis, computer programming and system analysis, to name a few. We studied theorems, corollaries, lemmas and what not. We studied proofs, solutions, and applications and wrote programs in computer languages. Once again it was pure mathematics. Neither our teachers, nor we ever bothered to see how what we learned also had connections to the cosmos. No one even ever bothered to keep our classrooms clean. We did make use of the dustbins if we saw them around. Otherwise, we disposed of garbage wherever we wanted.

In Mumbai, we knew the usefulness of nature when we spent our leisure time in the woods, an area inside the compound covered by trees. There were only a countable number of trees and it was hard to find a place where there was shade. Yet it was the most popular place for us to hang out. The little natural environment we had was very highly priced. We spent a lot of time chatting under those trees, discussing everything but mathematics while we sipped a cup of coffee or cool drinks.

A trip to a village during my third year BSc illustrated how distanced some of my city friends were from nature. Many of them were surprised to see for the first time a tomato or a chilli plant, a colourful rooster, an earthworm, how ugly/beautiful a caterpillar looked, how the air smelled different, how pleasant it was to hear the singing of the birds in the morning and how different the water tasted. I and a few others who had made these discoveries in childhood went around teasing them and boasting about our wonderful childhood. Apparently, this was the first time many of them had stepped out of the city and for the first time to a village. They were used to the concrete jungle of the city where connection to nature was minimal. Probably they had very little in terms of environmental education.

My masters' study life was a bit different. The college campus where I did my M. Sc. spanned about 100 acres in the city of Chennai. Anyone who has been to Chennai knows that the city has only three seasons: 'hot, hotter, and hottest!" So, the presence of every tree was precious, and we had many of them. Further, we suffered from acute water shortages very often in the campus. As a result, saving water was a concern and we were reminded about it every now and then in the hostel. Once again, the topics that I studied in the class never had much to do with cosmological concerns. I studied pure advanced mathematics and computer programming. Whatever connection I felt with nature was due to the weather and the necessity of saving water.

There was an aura of pride when I said I was doing BSc or MSc in pure mathematics.

But I failed to learn that

there are mathematical modelling and algorithms behind water resource management and hydrological forecasting; behind energy generation, preservation and allocation; behind weather prediction, fluid dynamics, forecasting extreme events (tsunamis, hurricanes, earthquakes) and risk management; behind analysing complex systems (like transportation and finance); behind understanding epidemic spread and virus infections; and behind ecological conservation (ICMI News 16: February 2011 as cited in Gellert, 2011, p. 20).

I consider adulthood as the time when one begins to make informed and conscious choices with regard to life. Since much of one's adulthood is spent in college studies, I believe what we learn in college guides our decision-making. When it comes to choices regarding environmental concerns, the college years would have been an important time in helping in this decision-making process. The critical role of higher education in caring for the 
environment is stressed by many researchers when they talk about sustainable education. Cortese (2003) says, "Higher education institutions bear a profound, moral responsibility to increase the awareness, knowledge, skills, and values needed to create a just and sustainable future" (p. 17). The author further mentions that higher education should take the leadership role in this sustainable education like it did for space and the arms race and other technological and medical advances. While criticizing the compartmentalization and disconnected specialization that is found in higher education, Cortese recommends an interdisciplinary thinking in the content and context of education, to enable students to see them as an integral part of nature and the responsibility towards caring for it.

Shephard (2008) claims that "the central element of education for sustainability is a quest for affective learning outcomes of values, attitudes and behaviours" (p. 95). He goes on to say that higher education must take into consideration this affective domain in order to achieve sustainable education. Besides suggesting interdisciplinary approaches, he also advocates that environmental themes be developed in subjects that are not directly related to environmental concerns. This would mean that mathematics should also involve such environmental themes. However, my university mathematics education did not include such themes in classrooms. Further, I can say that my university education failed to challenge many common assumptions like the following:

- Humans are the dominant species and separate from the rest of nature.

- Resources are free and inexhaustible.

- Earth's ecosystems can assimilate all human impacts.

- Technology will solve most of society's problems.

- All human needs and wants can be met through material means.

- Individual success is independent of the health and well-being of communities, cultures, and the life support system (Cortese, 2003, p. 17).

Jablonka (2003) considers environmental education an aim rather than a subject and, as a result, part of every subject. She recommends a new way of teaching-learning mathematics and calls it mathematical literacy. She says, "Mathematical Literacy for Environmental Awareness considers the possibilities of linking mathematical literacy not only to an individual's capacity to solve personal and local problems, but also to global environmental concerns" (p. 76). She goes on to add that the role of mathematics in the development of destructive technologies and its dehumanizing effect is often not taken into consideration. She believes that mathematical literacy would create a human view of mathematics and thus teaching-learning of mathematics would become more environmentally responsible. When I look back, I realize that my undergraduate and postgraduate studies of mathematics were not able to promote mathematical literacy in me. From them I did not imbibe the responsibility of mathematics teaching-leaning towards caring for the cosmos.

\section{The Awakening: Jesuit Life}

Probably the first time caring for nature became part of my life was when I began my life as a Jesuit. The core of the Ignatian Spirituality that I was taught to develop is to "find God in all things" because "God dwells in creatures giving them existence and God labours and works for me in all the creatures" (Loyola, 1993, p. 95). Similarly, the purpose of creation and everything else around us is to help us to "praise, reverence and serve God" for which human beings are created (p. 23).

From the very beginning of my training, I learned from one of my directors the importance of caring for nature. We planted trees, took care of them, watered them, protected them. When I went back after 25 years to the place where I had my initial training, I saw how 
the trees we planted had grown. I was happy to know that the level of water in the water source has gone up and many villagers also make use of it these days.

While doing my studies in Philosophy, the importance of caring for nature was better established. There I learned how every act of ours has an impact on nature. In the course on cosmology, science and religion, I learned the fact that we are only a minute part of this vast universe. Even though human beings are small particles, collectively we have caused so much damage to the universe.

I began to see the cosmic nature of my existence. When I learned about how Copernicus, Galileo, Clavius, Kepler, Carl Sagan and Stephen Hawking saw the universe, I realized not only my insignificance in the universe but also my responsibility towards it. I began to see the creation story of the Bible differently and understood its supposed meaning.

Caring for nature became a responsibility and not an option during my theological studies when the notion of sin was explained to us in our Moral Theology classes. While learning about sin, alienation from nature was one of the four manifestations of sin. This alienation takes place in many ways when I do not have the right relationship with creation. When I consider myself the master of creation instead of a part, I am alienated from creation. When I look at creation as a thing to be exploited for my selfish benefits, I am alienated from nature. When I destroy creation in the name of development, I am alienated from it. When I do not take care of it and do not do my bit in caring for the environment, I am alienated from it. Not having the right relationship with the cosmos meant that I was committing a sin. I learned that the Earth is something that is very special to God and He wants us to take care of it. "It is thus that God loves His Earth, enables it, enriches it, and makes it beautiful and fecund. And He places it in our hands so that we too may join Him in caring for it, may till it, keep it, humanize it, make it our home and our extended bodily self" (Rayan \& Kunnumpuram, 2013, p. 106).

During the General Congregation 35 of the Society of Jesus in 2008, the whole Society and its collaborators were called to establish a triptych of relationships with God, with others and creation. One of the three relationships was the right relationship with creation which encompasses the whole cosmos. The document invites, "Jesuits and those who share our mission to show ever more effective ecological solidarity in our spiritual, communal, and apostolic lives. This invitation calls us to move beyond doubts and indifference to take responsibility for our home, the earth" (JCSA, 2008, p. 79).

Subsequently, caring for creation thus became a commandment in our lives. We were urged to believe in the God of the cosmos and to become reconciled to it in establishing the right relationship with it. In order to achieve this reconciliation, we are called to a metanoia, a change of heart, and "to become agents of change ourselves. From the goodness of nature and the ethical vision of right relations we gain the spiritual energy to live lives of reconciliation between God, his creatures and ourselves" (Alvarez, 2010, p. 27)

I too was moved by such a clarion call and wanted to repair my relationship with creation. I began to practice a lot of pro-environmental activities. The three Rs -- Reduce, Reuse and Recycle -- became a mantra in my life in many ways. I saved water whenever I could. I reduced the use of paper or recycled it as much as possible. I used the dustbins and avoided littering. I avoided mineral water and carbonated drinks after hearing about the impact of their production on ground water. I turned off lights whenever I did not need them. I took part in tree plantations, took care of gardens and so on. Caring for the cosmos had become part of my life now but only as part of my mundane daily life. I did not do anything outside it. I was practicing environmentalism only in my private sphere and I never bothered to extend it to the public sphere (Chawla \& Cushing, 2007). It was mostly a spiritual awareness and practiced as a Jesuit than as a mathematics teacher-learner. Further, it never 
occurred to me in the initial years of my teaching days that my teaching-learning of mathematics had any connection to it.

\section{The Teaching Journey - from Total Alienation to Coming Closer}

My first teaching assignment was teaching mathematics in classes five and six. My initial energy was spent on establishing myself as a good 'mathematics' teacher. This meant that I taught mathematical concepts well, explained them clearly, ensured that students had enough practice and they did well in the examinations. Students had to be totally under my control; pin-drop silence was demanded when I spoke and absolutely no fooling around.

One of the first things that I did and do even now after I enter a class is to ask the students to pick any paper or type of garbage thrown on the floor. I could not bear a dirty floor or classroom and wanted the students to keep the classroom clean. Once the classroom was clean, I shifted into a different planet. The planet was my mathematics teaching-learning. There we were mathematical aliens who ate, drank, slept, and dreamt only mathematics. The students did it and the teacher facilitated it. Anything else was from a different planet and we would not entertain it. Caring for the environment was one of such aliens which I never wanted to visit my classrooms during the initial years of my teaching.

One fine day as I walked into the class, I saw a pool of blue ink on the floor. There was no way I was going to start the class with something of that sort on the floor.

I asked the class angrily, "Who is responsible for this?" When I realized that nobody would want to answer that, I changed my mode.

"Who would like to be responsible for cleaning it?" A boy and a girl from the back raised their hands first. Both were simple average students in mathematics. The so-called excellent students in mathematics did not want to take the responsibility for cleaning it. In fact, I came to know later that it was one of those excellent students who had knocked over the ink bottle accidently. That student was not taking responsibility for cleaning, either. When it came to cleaning, it was the average students who were proactive as if they had a better concern for the environment.

In the schools I was involved with, I supported and appreciated the efforts of the Eco Clubs and the Environment Clubs in promoting the care of the environment. As the principal, I ensured that the World Environment Day was celebrated on a mega scale by the whole school. There were cleaning campaigns, awareness programs, planting trees and what not on that day. Everyone in the school would be involved in one activity or another to mark the occasion. It never occurred to me that I should have used my mathematics classroom also for such activities not just on special occasions but daily. I kept such lessons for other subjects like Environmental Education.

While travelling through the city of Kathmandu and passing by the Bagmati River, I close my nose and complain about the insensitivity of the citizens of Kathmandu. During my mathematics teaching, I have made fun of the present situation of the Bagmati River and commented on the pathetic condition of the river. Should I not have connected what I taught to the preservation of the river? As a teacher, I should have been able to use my lessons in bringing awareness to the students about caring for the river instead of making fun of it. "What educators can influence are students' opportunities to gain knowledge, form positive attitudes about the environment, and practice action skills" (Chawla \& Cushing, 2007, p. 4). I missed such opportunities in my initial days of teaching.

Slowly I began to relate mathematics topics to students' lives. Initially, my attempts were to connect each topic in mathematics to at least one human value. As days went by, I began to experiment and explore more. Once I realized the intensity of the environmental and ecological crisis, I began to think how my mathematics lessons could be connected to 
environmental issues. In the process, I too began to discover the 'disconnect' that Renert (2011) talks about. He says, "As a mathematics teacher and researcher, I am experiencing a growing disconnect between the preoccupations of my professional life and the increasingly loud calls around me to attend to the problems of ecological sustainability." I realized that, like him, I too was "busy with metaphors of multiplication than to contemplate imminent environmental catastrophe" (p. 20).

I also read about the International Mathematical Union declaring 2013 as The Year of Mathematics of Planet Earth. It was a clarion call for all mathematicians and mathematical societies to wake up to the responsibility of mathematics towards the cosmos. The Union brought out four strategies to ensure that mathematics does not remain alienated from the concerns of Planet Earth. One of the four strategies was "Encourage mathematics teachers at all levels to communicate issues related to our Planet Earth through their instruction and their curriculum development" (Rousseau, 2012. p. 38). It was becoming clearer to the mathematical world that they could not distance mathematics from the environmental and ecological concerns any more. In fact, more than other subjects, mathematics had a major role in the present crisis. It was time for me to make my mathematics lessons cosmologically responsible.

The following are some ways I have attempted to connect mathematics teachinglearning to cosmological issues. I have tried some of them in my classes while others are still in the developing stages. Since I taught mostly in class ten, these lessons relate to topics in class ten.

While teaching the chapter on volume, I could talk about how a dripping tap wastes a huge volume of water. Students could be forming the habit of closing the taps properly and the value of saving water.

While teaching algebra, I could talk about the co-existence of living and non-living things, human beings and other living beings, referring to them as the number parts and the letter parts. The various operations could symbolize relationships between them.

While teaching height and distance, I could talk about how the terrace cultivation in the villages helps prevent landslides and promote agriculture.

I could also talk about missile and rocket technology, space exploration in a trigonometry class and show them how they have an impact on the environment.

While teaching lessons on mensuration, I could talk about saving paper by making use of every part of the paper properly. This could avoid wasting paper and thus save trees. When I tried this in my classes, many students began to make rough copies from the unused pages of old copies after hearing about saving paper.

I could bring in the concept of carbon footprint while teaching area and teach them how they can reduce their carbon footprint. Graphs and diagrams could be used to show various impacts of human behavior on environment by using appropriate examples.

Profit and loss lessons could be a means to impart knowledge about the harmful effects of pesticides and insecticides used by farmers to improve production and thereby profit.

\section{The Missing Link Found: MPhil Days}

When I joined the MPhil studies, I was not sure what was in store for me. I had come from a pure mathematics background. As the classes began, I realized that being pure only was a bad thing to happen; rather it should have been im/pure (Luitel, 2013). This meant that pure mathematical concepts had to be supplemented and complemented with real life situations and connections to make mathematical teaching-learning more meaningful. There were two courses that particularly challenged my experiences and assumptions of the teaching-learning 
of mathematics. The first one was the course on Dimensions in Mathematics Education. Here I discovered a number of issues that were limiting my own teaching practices.

The first issue that I discovered was the compartmentalization of subjects. There seems to be a watertight compartmentalization between subjects taught. Let me explain. It is often considered that environmental issues are a part only of the environmental subjects, value education is a part only of the value education or ethics classes, and civic sense is a part only of the civics classes and so on. As a result, such things are never part of mathematics. The age-old belief that mathematic is pure and the queen of sciences renders it an unwarranted superiority (Luitel \& Taylor, 2007). Consequently, mathematics should not be tainted with topics like equity, social justice, ecological concerns, spirituality and so on. They are the business of other subjects.

I was practicing the above policy verbatim in my teaching practices. On the one hand, I practiced pro-environmental behaviours in my life and encouraged students to do the same and, on the other hand, in my mathematics classes, I disconnected mathematics lessons from any environmental issues. So, my mathematics lessons had nothing to do with any environmental issues and failed in helping students discover the cosmological aspect of their lives. As I entered deeper into my MPhil studies, my reflections began to lead me from mere realizations to what I needed to do in the future. I recognized the urgent need to act for the future in my teaching-learning of mathematics. I needed to break the compartmentalization of mathematics from environmental education and cosmological issues.

The second course that changed my thinking was the one on curriculum. From the various metaphors for curriculum that I studied, I began to see the need to go beyond the cognitive dimension of education. In particular, I came to know that a proper curriculum must be also concerned about the environment and ecology. This notion of curriculum connected to nature and ecology was very strong in the metaphor curriculum as a garden proposed by Baptist (2002). The garden metaphor portrays the close connection that a student must have with nature not only in terms of learning, but also in applying what is learned in the classroom. Consequently, mathematics lessons also must have such connections made in the classrooms.

On the one hand, the reflective learning in my MPhil classes corroborated the little efforts that I had initiated in my classes while, on the other hand, it also raised the need to do more. It was time for me to green myself and my mathematics teaching-learning. "The greening of the self involves a moving beyond the 'separateness, alienation, and fragmentation' constitutive of the dichotomous self and other" (Riley-Taylor, 2002, p. 122). In order to accomplish the greening of my mathematics teaching-learning, I needed to come out of the "separateness, alienation, and fragmentation" that have been part of it since my childhood and to some extent part of its history.

Furthermore, greening myself entails a new worldview, a new cosmology wherein I do not see myself as separate from the cosmos but rather as part of it, in it and the cosmos being part of me. This new cosmological view "recognizes the dynamic interplay between all forms, human and non-human, as contributing to a process which is fundamentally based on diversity" (Riley-Taylor, 2002, p. 100). A new ecospiritual praxis must be my way of life whereby I become strongly aware about my place within the larger cosmos, my responsibility towards it and ushering in change in my attitudes and behaviour through reflection (RileyTaylor, 2002). This is the kind of wisdom that my father, many other elders and indigenous people applied even though they did not have the kind of education that I had. I hope such an ecospiritual praxis and wisdom will enable my mathematics teaching-learning to be more cosmologically responsible. 


\section{Conclusion}

As a mathematics educator, I have grown in my relationship with the cosmos. I no longer see mathematics as alienated from cosmological concerns; rather I see cosmological concerns as an integral part of my mathematics teaching-learning. As a student of mathematics, I experienced almost complete alienation of my relationship with the cosmos from the topics I learned even though I lived very close to nature and interacted mathematically with it very often. However, caring for the environment and enhancing my relationship with the cosmos were not part of my learning. As a Jesuit, my relationship with the cosmos became a spiritual endeavour while it did not affect the mathematician in me. Thanks to the Ignatian Pedagogical Paradigm and MPhil studies, the mathematics educator in me eventually has comprehended the importance of mathematics becoming cosmologically responsible.

Through the personal reflections on my experiences that I undertook during this inquiry, I have consolidated the need to green myself more and my mathematics teachinglearning as well. I want to ensure that my mathematics teaching-learning is cosmologically responsible by using my lessons to promote pro-cosmological behaviours among students. I want to establish connections between mathematical topics and the cosmological issues in order to raise awareness in students, challenge their beliefs and motivate them to action towards caring for the cosmos. I also believe that with more creativity and greater effort, teachers can make mathematics cosmologically responsible and promote pro-cosmological behaviour in students. If we can overcome our compartmental and puritanical perspective of mathematics teaching-learning, it will empower not only the teachers concerned, but also their students to relate positively with the cosmos in their lives. This will guarantee that unlike in the past, our lives become beneficial to other human beings, other living beings and the universe. In my life, the journey of making mathematics cosmologically responsible has only begun and I know there are miles to go.

\section{Acknowledgments}

I would like to thank all my Jesuit companions for being there whenever I needed any help during my inquiry. I am highly obliged to those University family who taught me to think out of the box regarding mathematics education and also for all the other assistance I received for the completion of this article.

\section{Funding}

I have not received any funding for doing this research.

\section{List of References}

Alvarez, P. (2010). Healing a broken world. https://www.sjweb.info/sjs/PJnew/

Baptist, K. W. (2002). The garden as metaphor for curriculum. Teacher Education Quarterly, 29(4), 19-37.

Chawla, L., \& Cushing, D. F. (2007). Education for strategic environmental behavior. Environmental Education Research, 13(4), 437-452.

Coertjens, L., Boeve-de Pauw, J., De Maeyer, S., \& Van Petegem, P. (2010). Do schools make a difference in their students' environmental attitudes and awareness? Evidence from PISA 2006.

Cortese, A. D. (2003). The critical role of higher education in creating a sustainable future. Planning for Higher Education, 31(3), 15-22. 
Duerden, M. D., \& Witt, P. A. (2010). The impact of direct and indirect experiences on the development of environmental knowledge, attitudes, and behavior. Journal of Environmental Psychology, 30(4), 379-392. P. 391

Gellert, U. (2011). Now it concerns us! A reaction to sustainable mathematics education. For the Learning of Mathematics, 31(2), 19-20.

Hawking, S. (2017). Brainy quote. https://www.brainyquote.com/quotes/quotes/s/stephenhaw627095.html

Hesse, H. (1922). Siddhartha (Hilda Rosner, Trans.). Rupa and Co.

Holley, P. (2017). Stephen Hawking just moved up humanity's deadline for escaping Earth. https://www.washingtonpost.com/news/speaking-of-science/wp/2017/05/05/stephenhawking-just-moved-up-humanitys-deadline-for-escapingearth/?utm_term=.fbca5f82ec17

Jablonka, E. (2003). Mathematical literacy. In Second international handbook of mathematics education (pp. 75-102). Springer.

Jesuit Conference of South Asia. (2008). Decrees of General Congregation, 35.

Kollmuss, A., \& Agyeman, J. (2002). Mind the gap: why do people act environmentally and what are the barriers to pro-environmental behavior? Environmental Education Research, 8(3), 239-260.

Liefländer, A. K., Fröhlich, G., Bogner, F. X., \& Schultz, P. W. (2013). Promoting connectedness with nature through environmental education. Environmental Education Research, 19(3), 370-384.

Loyola, I. (1993). The Spiritual Exercises of St. Ignatius, Ganss, GE, SJ (Trans.). Gujarat Sahitya Prakash.

Luitel, B. C. (2012). A multi-paradigmatic approach to researching lived experiences in Mathematics education: Contemplating possible connections. A paper from an International STEM Research Symposium WISDOMe Monograph\# 3. WY: University of Wyoming.

Luitel, B. C. (2013). Mathematics as an im/pure knowledge system: symbiosis, (w) holism and synergy in mathematics education. International Journal of Science and Mathematics Education, 11(1), 65-87.

Luitel, B. C., \& Taylor, P. C. (2007). The Shanai, the Pseudosphere and other imaginings: Envisioning culturally contextualised mathematics education. Cultural Studies of Science Education, 2(3), 621-655.

McAvoy, M. E. (2013). Training Faculty to Adopt the Ignatian Pedagogical Paradigm, IPP and its Influence on Teaching and Learning: Process and Outcomes. Jesuit Higher Education: A Journal, 2(2), 61-109.

Mezirow, J. (1997). Transformative learning: Theory to practice. New directions for adult and continuing education, 1997(74), 5-12.

Mezirow, J. (2003). Transformative learning as discourse. Journal of transformative education, 1(1), 58-63.

Painadath, S. (2009). The power of silence. ISPCK.

Pope Francis, (2013). Encyclical Letter Laudato Si'of the Holy Father Francis: On Care for Our Common Home. Vatican Website.

Rayan, S., \& Kunnumpuram, K. (2013). Selected writings of Samuel Rayan. St. Paul's.

Renert, M. (2011). Mathematics for life: Sustainable mathematics education. For the Learning of Mathematics, 31(1), 20-26.

Riley-Taylor, E. (2002). Chapter Four: An Ecospiritual Ethic and Decisions of Responsibility. Counterpoints, 201, 97-124.

Rousseau, C. (2012). Mathematics of Planet Earth 2013. Notices of the American Mathematical Society, 59(1), 5-6. 
Shephard, K. (2008). Higher education for sustainability: seeking affective learning outcomes. International Journal of Sustainability in Higher Education, 9(1), 87-98.

Taylor, P. C., \& Medina, M. (2011). Educational research paradigms: From positivism to pluralism. College Research Journal, 1(1), 1-16.

Tolle, E. (2003). Stillness speaks. Yogi Impressions.

\section{Suggested Citation:}

Varghese, J. (2020). Connecting mathematics teaching-learning to my relationship with the cosmos. Journal of Transformative Praxis, 1(1), 9-24. 